\title{
Review
}

\section{Ketamine use in current clinical practice}

\author{
Mei $\mathrm{GAO}^{1,2}$, Damoon REJAEI ${ }^{2}$, Hong $\mathrm{LIU}^{2, *}$ \\ ${ }^{1}$ Department of Anesthesiology, the First Affiliated Hospital of Nanjing Medical University, Nanjing 210029, China; ${ }^{2}$ Department of \\ Anesthesiology and Pain Medicine, University of California Davis Health System, Sacramento, CA 95817, USA
}

\begin{abstract}
After nearly half a century on the market, ketamine still occupies a unique corner in the medical armamentarium of anesthesiologists or clinicians treating pain. Over the last two decades, much research has been conducted highlighting the drug's mechanisms of action, specifically those of its enantiomers. Nowadays, ketamine is also being utilized for pediatric pain control in emergency department, with its anti-hyperalgesic and anti-inflammatory effects being revealed in acute and chronic pain management. Recently, new insights have been gained on ketamine's potential anti-depressive and antisuicidal effects. This article provides an overview of the drug's pharmacokinetics and pharmacodynamics while also discussing the potential benefits and risks of ketamine administration in various clinical settings.
\end{abstract}

Keywords: ketamine; pain management; pediatric caudal anesthesia; anti-depressive medication; anti-suicidal effects; antiinflammation

Acta Pharmacologica Sinica (2016) 37: 865-872; doi: 10.1038/aps.2016.5; published online 28 Mar 2016

\section{Introduction}

Ketamine was first synthesized in 1962 by Calvin Stevens at Parke-Davis Co (now Pfizer) as an alternative anesthetic to phencyclidine. It was first used in humans in 1965 by Corssen and Domino and was introduced into clinical practice by 1970. Ketamine is frequently described as a "unique drug" because it shows hypnotic (sleep-producing), analgesic (pain-relieving) and amnesic (short-term memory loss) effects; no other drug used in clinical practice produces these three important effects at the same time.

\section{Pharmacokinetics (PK) and pharmacodynamics (PD)}

Ketamine is chemically (+/-) 2-(2-chlorophenyl)-2-(methylamino)-cyclohexanone with the chemical formula: $\mathrm{C}_{13} \mathrm{H}_{16} \mathrm{ClNO}$ and a molecular weight of 274.4. It has a chiral structure consisting of two pure optical isomers, named $S$ - and $R$-ketamine, with each racemate composed of both isomers in equal amounts. The anesthetic potency of the $S(+)$-isomer is approximately three or four times that of the $R(-)$-isomer ${ }^{[1]}$. In vivo, there is a statistically significant $(P<0.01)$ smaller clearance and volume of distribution for $R(-)$-ketamine compared with $S(+)-$ ketamine $^{[2]}$. Several animal studies have shown that the clearance and volume of distribution of ketamine are related to hepatic blood flow, which can be predicted in humans ${ }^{[3]}$.

\footnotetext{
* To whom correspondence should be addressed.

E-mail hualiu@ucdavis.edu

Received 2015-10-04 Accepted 2016-01-19
}

In human studies, hepatic cytochrome P450 (CYP3A4) has been found to be the primary enzyme responsible for the $\mathrm{N}$-demethylation of ketamine to norketamine, while in animals and in vitro, CYP2B6, CYP3A4 and CYP2C9 are the main enzymes responsible for its metabolism ${ }^{[4,5]}$. Un-metabolized ketamine and its metabolites (ie, norketamine) are excreted in the urine.

Since the 1980s, ketamine's mechanism of action has been considered to be mainly a noncompetitive antagonism of the $N$-methyl-D-aspartic acid (NMDA) receptor ${ }^{[6,7]}$. It was discovered in later research that ketamine also targets other receptors, such as a-amino-3-hydroxy-5-methyl-4isoxazolepropionic acid (AMPA) receptors, and has additional acts as an agonist of the sigma 1 receptor ${ }^{[8]}$. The dissociated effect is related to the high degree of phencyclidine site occupancy of NMDA receptors ${ }^{[8]}$.

\section{Modes of administration}

Ketamine is water and lipid soluble, allowing it to be administered conveniently via various routes that emphasize its adaptability to many clinical scenarios ${ }^{[9]}$. The optimal route of administration of ketamine is intravenous (iv), but this is not always achievable in emergencies, children and obese patients. Improvements in obtaining intraosseous (io) access have made this route of administration more efficient ${ }^{[10-12]}$. The intramuscular (im) route has been used for decades, and it is safe and predictable, although painful upon injection. Compared to iv, the im route is associated with longer recovery time and 
a higher rate of vomiting ${ }^{[13]}$. The oral bioavailability of ketamine is low ${ }^{[14]}$, but with small doses per os (po) S-ketamine can be assumed to be a feasible alternative to repeated intravenous injections, especially in the setting of chronic pain ${ }^{[15]}$. Intranasal (in) administration is also an option. Indeed, rapid systemic absorption, combined with the ease of access, makes this route appealing ${ }^{[16]}$. Overall, there are different doses from different administration routes (Table 1$)^{[9,16-20]}$. However, whatever the route chosen, ketamine should be titrated to the required clinical effect.

Table 1. Route of administration and the starting dose of ketamine.

\begin{tabular}{|c|c|}
\hline Route of administration & Starting dose \\
\hline Intravenous & $\begin{array}{l}0.25-1 \mathrm{mg} / \mathrm{kg} \text { (adults) } \\
0.25-2 \mathrm{mg} / \mathrm{kg} \text { (children) } \\
1-2 \mathrm{mg} / \mathrm{kg}^{*} \text { (adults) } \\
2-6 \mathrm{mg} \cdot \mathrm{kg}^{-1} \cdot \mathrm{min}^{-1} \text { (children) }^{\#}\end{array}$ \\
\hline Intraosseous & $\begin{array}{l}0.5-1 \mathrm{mg} / \mathrm{kg}^{*} \\
1-2 \mathrm{mg} / \mathrm{kg}^{\#}\end{array}$ \\
\hline Intramuscular & $\begin{array}{l}4-5 \mathrm{mg} / \mathrm{kg}^{*[17]} \\
8-10 \mathrm{mg} / \mathrm{kg}^{\#[17]}\end{array}$ \\
\hline By mouth & $\begin{array}{l}3-15 \mathrm{mg} / \mathrm{kg} \text { (children) }^{*[9,18]} \\
500 \mathrm{mg} \text { maximum (adults) }\end{array}$ \\
\hline Intranasal & $\begin{array}{l}0.25-4 \mathrm{mg} / \mathrm{kg}^{*[16,19,20]} \\
3-9 \mathrm{mg} / \mathrm{kg}^{\#[16,19,20]}\end{array}$ \\
\hline
\end{tabular}

*Analgesa and sedation dose; ${ }^{*}$ Anesthesia dose.

\section{Side effects}

Ketamine has been shown to increase the incidence of postoperative nausea and vomiting (PONV), while also increasing the severity of nausea ${ }^{[21]}$. One of ketamine's positive features is that it has a minimal effect on the central respiratory drive if given slowly, although rapid iv injection can cause transient apnea. Ketamine increases salivary secretions, which may increase the incidence of laryngospasm. This may be due to partial airway obstruction and can be resolved by simple airway maneuvers. Secretions can be anticipated; therefore, it is recommended to co-administer a small dose of atropine (0.01 $\mathrm{mg} / \mathrm{kg})^{[22]}$.

When used in sub-anesthetic doses, ketamine provokes imaginative, dissociative states and psychotic symptoms resembling schizophrenia due to its NMDA-antagonistic action, as well as severely impairing semantic and episodic memory. Used as an anesthetic, it can cause various emergent phenomena that have been described as a floating sensation, vivid pleasant dreams, nightmares, hallucinations and delirium. These phenomena are more common in patients $>16$ years of age, females, shorter operative procedures, and those receiving large doses, particularly when administered quickly.
Animal studies suggest that neurodegeneration, with possible cognitive sequelae, is a potential long-term risk of anesthetics in neonatal and young pediatric patients ${ }^{[23]}$. Numerous animal studies in rodents indicate that ketamine induces neurodegeneration in the developing brain in a dose-depended manner, and the data also suggest that limiting exposure limits the potential for neurodegeneration. Some postnatal preclinical studies suggested that ketamine-induced injury in the infant rodent brain was a centrally driven event ${ }^{[24,25]}$. There are very few studies that have examined the potential functional consequences of the neurodegeneration noted in the animal models, except recent evidence suggests that multiple exposures to anesthetics (including ketamine) and surgery before the age of 2 was a significant independent risk factor for the later development of learning disabilities ${ }^{[26]}$. Although the doses and durations of ketamine exposure that resulted in neurodegeneration were slightly larger than those used in the clinical setting, there are insufficient human data to either support or refute the clinical applicability of these findings ${ }^{[23]}$.

A syndrome of cystitis and contracted bladder can be associated with street ketamine abuse. Secondary renal damage occurred in severe cases, which may or may not be irreversible, rendering patients dependent on dialysis ${ }^{[27,28]}$. Another side effect frequently present in ketamine abusers was upper gastrointestinal symptoms, the most common of which was epigastric pain $(73 \% \text { of abusers in one retrospective study })^{[29]}$.

\section{Historical uses: anesthesia in the operating room}

Ketamine has been used in the operating room for nearly 50 years. The bronchial dilatory profile of ketamine makes the induction and maintenance of anesthesia safer in patients with asthma and life-threatening acute bronchial constriction. Because of the favorable cardiovascular characteristics, stimulating the central sympathetic system and inhibiting neuronal catecholamine uptake, ketamine is preferred in patients with unstable hemodynamics. Ketamine is also one of the very few drugs approved for anesthesia induction in caesarean sections. It is considered the agent of choice in children and burn victims $^{[30]}$. Additionally, administration of ketamine during induction, at least in patients with cardiopulmonary bypass, may attenuate post-operative delirium ${ }^{[31]}$.

\section{Current uses}

After more than half a century since its discovery, ketamine has emerged as a promising drug for pain management, antidepression and anti-inflammation.

\section{Acute pain management}

\section{Pre- and post-operative pain management}

Opioids are traditionally an integral part of therapy for acute post-operative pain. Unfortunately, possible hyperalgesia from opioids can result in increased analgesic requirements. However, ketamine can block these mechanisms; when administered at sub-anesthetic and repeated doses, ketamine has been shown to prevent the development of increased pain sensitivity and opioid tolerance ${ }^{[32]}$. The analgesic effects of ket- 
amine are mediated primarily via NMDA receptors and partially via opioid receptors. A pre-emptive bolus dose of ketamine $(0.1 \mathrm{mg} / \mathrm{kg})$ has opioid-sparing effects in opioid abusers undergoing moderate sedation ${ }^{[33]}$. A study of intrinsic functional brain connectivity in twelve healthy volunteers, through resting state functional magnetic resonance imaging, found obvious changes in certain regions of the central nervous system (ie, the amygdala, insula, and anterior cingulate cortex), which could explain ketamine's pharmacodynamic profile with respect to analgesia and its psychedelic side effects ${ }^{[34]}$. For post-operative pain, sub-anesthetic doses of ketamine are effective at reducing morphine requirements in the first $24 \mathrm{~h}$ after surgery, as well as reducing PONV. After cholecystectomy, $2 \mathrm{mg} / \mathrm{kg}$ ketamine administered subcutaneously versus $1 \mathrm{mg} / \mathrm{kg}$ iv $15 \mathrm{~min}$ before surgery provided better pain control for $24 \mathrm{~h}^{[35]}$. Administering $0.5 \mathrm{mg} / \mathrm{kg}$ ketamine upon induction, followed by $10 \mu \mathrm{g} \cdot \mathrm{kg}^{-1} \cdot \mathrm{h}^{-1}$ until wound closure, decreases perioperative opiate requirements in opiate-dependent patients with chronic back pain undergoing back surgery ${ }^{[36]}$. Hasanein and colleagues ${ }^{[37]}$ investigated the administration of low-dose intra-operative ketamine in laparoscopic Rouxen-Y gastric bypass (LRYGB) and demonstrated improved pain scores and reduced post-operative opioid requirements. Feltracco and colleagues ${ }^{[38]}$ showed that epidural infusion of sub-anesthetic doses of $S(+)$-ketamine during thoracic surgery provides better post-operative analgesia than epidural ropivacaine. A study on the combination of oral clonidine premedication and intra- and post-operative sub-anesthetic ketamine administration showed a reduction in iv patient controlled analgesia (PCA) morphine requirements. Neither clonidine nor ketamine alone reduced the post-operative PCA morphine requirements in patients undergoing spine surgery ${ }^{[39]}$. Atashkhoyi ${ }^{[40]}$ concluded that the use of low-dose ketamine with propofol-fentanyl anesthesia in patients undergoing diagnostic laparoscopy for gynecological procedures was associated with less pain during propofol injection, a lower incidence of hemodynamic changes, lower total propofol requirements and improved post-operative analgesia. However, not all trials have shown such promising results for the use of ketamine.

In a study performed by Bauchat and colleagues, $10 \mathrm{mg}$ iv ketamine supplementing spinal bupivacaine, fentanyl, and morphine, and iv ketorolac after cesarean section had no additional post-operative analgesic benefit ${ }^{[41]}$, which contradicted a later similar study that showed that the administration of $S$-ketamine via a 12 -h infusion was safe and provided better pain control in repeat cesarean section patient populations ${ }^{[42]}$. The combination of ketamine $\left(5 \mathrm{mg} \cdot \mathrm{kg}^{-1} \cdot \mathrm{min}^{-1}\right)$ and remifentanil $\left(0.4 \mathrm{mg} \cdot \mathrm{kg}^{-1} \cdot \mathrm{min}^{-1}\right)$ for cholecystectomy did not alter the severity of post-operative pain, time to first analgesic supplementation or total morphine requirements in $24 \mathrm{~h}^{[43]}$. No improvement in post-operative analgesia was conveyed after cesarean section when $0.25-1 \mathrm{mg} / \mathrm{kg}$ ketamine was added to anesthesia induction ${ }^{[44]}$. Similarly, anesthesia with propofol-ketamine versus propofol-alfentanil for dilatation and curettage was comparable, but the ketamine group required more time before orientation returned ${ }^{[45]}$. Given the various outcomes from the aforementioned studies, one can only conclude that larger, multi-center, double-blinded, randomized trials are needed to provide more evidence for the efficacy of ketamine in various clinical scenarios.

\section{Use outside the operating room}

Ketamine is a nearly ideal agent for use outside the operating room in maintaining homeostasis (cardiovascular stability, maintenance of respiratory reflexes), especially in shock patients who require ongoing resuscitation and maximal sympathetic activity ${ }^{[46,47]}$. Recent publications have shown evidence for ketamine's role in neuroprotection ${ }^{[48]}$. As such, ketamine is appropriate for patients with traumatic brain injury. Moreover, given the possible impairment in cerebral auto-regulation in traumatic brain injury, the brain's perfusion pressure becomes critically dependent on mean arterial pressure, rendering a clinical scenario in which ketamine's cardiovascular stability may be beneficial ${ }^{[49]}$. Ketamine is a useful analgesic drug for use outside the operating room due to its excellent analgesia, which is similar to morphine or fentanyl, but with a lower incidence of respiratory depression, as demonstrated in pain control for patients with fractures, burns, and traumatic amputations ${ }^{[50,51]}$. As a result, ketamine plays an important role in procedural sedation in the emergency department (ED), including during pediatric emergencies. Its use in disaster situations and limited resources is also well documented ${ }^{[52]}$. Currently, ketamine is increasingly used in conjunction with propofol, called "ketofol", which is the mixture of ketamine and propofol in a single syringe. This is performed for adult procedural sedation in the ED because the opposing physiological effects of ketamine and propofol are beneficial during emergency situations - ketamine mitigates propofol-induced hypotension, and propofol mitigates ketamine-induced vomiting and recovery agitation ${ }^{[53]}$. Accordingly, a retrospective case analysis suggested that sedation with the combination of ketamine and propofol can be safely performed in the pediatric ED by a skilled emergency physician $^{[54]}$. The use of ketamine, $1.0 \mathrm{mg} / \mathrm{kg}$ iv followed by $0.5 \mathrm{mg} / \mathrm{kg}$ every $3 \mathrm{~min}$ as needed, was safe and effective for procedural sedation ${ }^{[55]}$. Additionally, propofol in conjunction with $0.5 \mathrm{mg} / \mathrm{kg}$ ketamine, compared with propofol alone, may result in less hemodynamic depression, which may be advantageous in patients with unstable hemodynamics in the $\mathrm{ED}^{[56]}$. Ketamine combined with midazolam is a reasonable choice for orthopedic interventions in the emergency unit because of the lower risk for hypoxia and lower pain scores ${ }^{[57]}$. Low-dose ketamine combined with a reduced dose hydromorphone protocol produced rapid, profound pain relief without significant side effects in a diverse cohort of ED patients with acute pain $^{[58-60]}$. Sub-dissociative intravenous ketamine administered at $0.3 \mathrm{mg} / \mathrm{kg}$ provides analgesic effectiveness and apparent safety comparable to that of intravenous morphine in the short-term treatment of acute pain in the $\mathrm{ED}^{[61]}$.

Intranasal ketamine, a convenient route of administration, reduced visual analog scale (VAS) pain scores to a clinically significant degree in $88 \%$ of ED patients in a prospective obser- 
vational series $^{[62]}$. An average dose of $1.0 \mathrm{mg} / \mathrm{kg}$ intranasal ketamine provided adequate analgesia by 30 min for most ED children, aged 3-13 years and with moderate to severe $(\geq 6 / 10)$ pain from isolated limb injury ${ }^{[63]}$. Manual and semiautomatic io techniques of ketamine administration in the prehospital setting are often used in Australia ${ }^{[64]}$.

\section{Pediatric use}

A recent quantitative systematic review of randomized controlled trials on adding ketamine to pediatric caudal anesthesia concluded that ketamine prolonged analgesia with few side effects compared with local anesthetic alone ${ }^{[65]}$. Another meta-analysis stated that caudal ketamine in pediatric patients was associated with decreased post-operative pain and nonopioid analgesic requirements ${ }^{[66]}$. When $0.5 \mathrm{mg} / \mathrm{kg}$ of ketamine was added to $1 \mathrm{mcg} / \mathrm{kg}$ fentanyl, analgesia improved without delaying hospital discharge after a tonsillectomy ${ }^{[67]}$. Additionally, $0.5 \mathrm{mg} / \mathrm{kg}$ ketamine with $5 \%$ sevoflurane and alfentanil $10 \mathrm{mcg} / \mathrm{kg}$ improved intubating conditions in children, while preserving spontaneous breathing and hemodynamic stability ${ }^{[68]}$. During pediatric cleft palate surgeries, surgical site infiltration with either bupivacaine or ketamine provides adequate analgesia without major side effects. Moreover, ketamine is superior to bupivacaine in terms of requiring rescue analgesia, promoting a peaceful sleep pattern and the early resumption of feeding ${ }^{[69]}$. Javid and colleagues ${ }^{[70]}$ demonstrated that both subcutaneous and intravenous injections of ketamine at the end of surgery were safe and effective for post-tonsillectomy pain control without increasing the risk of complications. Two separate studies found the topical application of tramadol and ketamine to be a safe, effective, and easy analgesic approach for decreasing post-tonsillectomy pain $^{[71,72]}$. Nielsen ${ }^{[73]}$ suggested that a sufentanil and ketamine nasal spray provides a rapid onset of analgesia for a variety of painful procedures with few adverse effects and has promising features for use in pediatric procedural pain management. A prospective, randomized, double-blind study that included patients from 1 to 5 years old, with burn areas up to $10 \%$ of total body surface area that required bedside wound care, showed that the combination of oral midazolam and ketamine provided better analgesia than the combination of midazolam, acetaminophen, and codeine ${ }^{[74]}$. Conversely, a different study did not support the use of perioperative low-dose ketamine to decrease opioid use in children with scoliosis undergoing posterior spinal fusion ${ }^{[75]}$. The potential for a combination of drugs to induce greater or less neurotoxicity is not clear. However, recent laboratory data suggest that some combinations may be more neurotoxic than the individual components. Therefore, clinicians are advised to attempt to minimize exposure to potentially toxic drugs when possible. It is important to consider alternative therapies and watch for new developments ${ }^{[23]}$.

\section{Chronic pain management}

Chronic pain usually is the result of central sensitization or neuropathic processes with hyperalgesia or allodynia. The effects on NMDA receptors play an important role for ket- amine in chronic pain management ${ }^{[76]}$. Most recently, ketamine has been used to treat various chronic pain syndromes, especially those that have a neuropathic component, and cancer pain ${ }^{[77,78]}$. Low dose ketamine produces strong analgesia in neuropathic pain states, presumably by inhibition of the NMDA receptor, although other mechanisms are possibly involved, including enhancement of descending inhibition and anti-inflammatory effects acting centrally. However, the long-term effectiveness of ketamine to treat chronic pain remains controversial, as studies often demonstrate contradicting results. A prospective, randomized, double-blinded study demonstrated that a post-operative ketamine infusion at $0.2 \mathrm{mg} \cdot \mathrm{kg}^{-1} \cdot \mathrm{h}^{-1}$, in addition to opioids, resulted in a statistically significant reduction of "average" pain scores in patients undergoing surgery who take opioids for chronic pain. However, "least" and "worst" pain scores and the amount of opioid used post-operatively did not differ from the control group $^{[79]}$. Another randomized trial concluded that multi-day low dose ketamine infusions as an adjuvant to gabapentin in post-spinal cord injury related chronic pain is safe and efficacious in reducing pain, but the effect compared to placebo ceased 2 weeks after infusion termination ${ }^{[80]}$. One study of 185 participants, in a dose-escalation, double-blind, randomized, placebo-controlled phase III trial, where ketamine or the placebo were delivered subcutaneously over 3 to $5 \mathrm{~d}$, concluded that ketamine does not have a net clinical benefit when used as an adjunct to opioids and standard co-analgesics in cancer pain ${ }^{[81]}$. A study on patients undergoing thoracotomy suggested that adding epidural or iv racemic ketamine to thoracic epidural analgesia after thoracotomy did not lead to any reduction in persistent post-surgical pain or allodynia ${ }^{[82]}$. Ketamine could be an alternative choice for pain therapy in patients with chronic pain where standard analgesics, such as opioids, or other treatments are insufficient ${ }^{[83]}$. This includes the reduction of allodynia and hyperpathia in cancer pain, fibromyalgia, ischemia, phantom pain and in complex regional pain syndromes. These views coincide with our own, but additional large sample studies are needed to determine the optimal dose and timing of perioperative ketamine that are both safe and effective for patients with chronic pain and longterm opioid use.

\section{Perspective use: anti-depressive and anti-suicidal effects}

Ketamine has proved to be an extremely effective treatment for major depression, bipolar disorder and suicidal behavior. The slow onset and moderate degrees of receptor occupancy could largely be used to avoid the anesthesia effect, dissociation and psychotomimetic reactions. However, a debate is ongoing as to whether it is the direct actions of ketamine at the phencyclidine site on the NMDA receptor that account for its actions, or the downstream stimulation of AMPA receptors ${ }^{[8]}$. Ketamine works incredibly fast, lifting depression in as little as two hours, which is unlike conventional anti-depressants that generally take weeks to start working ${ }^{[84,85]}$. The images of $\left[{ }^{18} \mathrm{~F}\right]$-fluorodeoxyglucose (FDG) positron emission tomography (PET) on 21 subjects with bipolar disorder in a 
depressed state showed a distinct change in metabolism in the subgenual anterior cingulate cortex, which may explain the anti-depressant response to ketamine ${ }^{[86]}$. The findings of one meta-analysis added to the existing evidence that support ketamine as a novel treatment option for depression, stating that ketamine has been shown to have a high response rate and rapid effect ${ }^{[87]}$. Several independent pilot studies demonstrate that after a single intravenous infusion of sub-anesthetic dosages of ketamine, its anti-depressant effects have an onset within hours and are sustained for an average of 4-7 $\mathrm{d}^{[88,89]}$. A systematic review also showed ketamine to be a rapid and effective treatment option for depression, as well as reducing suicidal ideation, with minimal short-term side effects ${ }^{[90]}$. Furthermore, evidence reported in the literature from studies with single and multiple doses of ketamine also showed that some subjects might be able to sustain the response for weeks to months ${ }^{[91,92]}$. Studies to date suggest intravenous ketamine produces substantial reductions in suicidal ideation in patients with unipolar and bipolar depression, in both uncontrolled and randomized controlled trials. Large reductions have been observed in as early as 40 min post-infusion, with improvements maintained for variable amounts of time ranging from 230 min up to $10 \mathrm{~d}$ post-infusion ${ }^{[93]}$. Price and colleagues ${ }^{[94]}$ conducted a randomized controlled trial in treatment-resistant depression, which showed that intravenous ketamine produces rapid reductions in suicidal cognition over and above active placebo. Additionally, a retrospective medical record review of thirty-one cases suggested that ketamine may be a safe, effective, and rapid treatment for clinical depression in patients receiving hospice care ${ }^{[95]}$. Overall, ketamine has potential as a rapid treatment for treatment-resistant depression and suicidal ideation and may be a possible model compound for future drug development. However, additional studies are needed to further investigate its mechanism of action, long-term outcomes, and long-term adverse effects (including abuse) and benefits.

\section{Anti-inflammation}

De Kock and colleagues ${ }^{[96]}$ believe that ketamine appears to promote inflammatory homeostasis and is an immunomodulatory rather than immunosuppressive drug. Locally, ketamine interferes very early with the determinants of primary immunity. It prevents the exacerbation and the extension of local inflammation without blunting the local process and delaying inflammatory resolution. In both animal experiments and human observation, ketamine also prevents the general antipro-inflammatory mechanisms to excessively overcome the pro-inflammatory influences ${ }^{[96]}$. Combinations of ketamine and atropine are neuroprotective and reduce neuroinflammation after toxic status epilepticus in mice ${ }^{[97]}$. In a systematic review of clinical studies, the authors concluded that intraoperative ketamine exerts anti-inflammatory effects ${ }^{[98]}$. Most relevant clinical data support this conclusion. Ketamine, as an NMDA antagonist, can suppress $\mathrm{T}$ helper cell differentiation and subsequent cytokine production in vitro ${ }^{[99,100]}$. It also has a morphine-sparing effect after total hip arthroplasty, even when morphine is combined with multimodal systemic analgesia. It also facilitated rehabilitation at 1 month and decreased postoperative chronic pain up to 6 months after surgery ${ }^{[101]}$. One study demonstrated that $S(+)$-ketamine $(1-3 \mathrm{mg} / \mathrm{kg}$ bolus, followed by 2-4 $\left.\mathrm{mg} \cdot \mathrm{kg}^{-1} \cdot \mathrm{h}^{-1}\right)$ during elective coronary artery bypass graft surgery exerts anti-inflammatory effects during and after cardiopulmonary bypass ${ }^{[102]}$. Although these studies were based on inflammatory markers, large prospective human studies are warranted for clinical outcomes.

\section{Conclusions}

Ketamine is a special example of how an old drug can be readapted for new applications. The mechanisms of ketamine's effects are mainly related to its inhibition of the NMDA receptor and its pathway. It has the potential to become a first-line anti-depressive medication, especially for refractory major depression, as well as suicidal ideation in unipolar and bipolar disorders. Moreover, it is also an effective adjuvant that prolongs the duration of a single-medication for pain management in the ED and is a safe choice for children to alleviate surgery-related pain. While the current literature provides evidence for acute relief of chronic neuropathic pain, evidence supporting the efficacy and tolerability of ketamine for the long-term treatment of chronic pain is still limited. Finally, ketamine also appears to have local and general antiinflammatory effects, the benefit of which remains to be elucidated.

\section{References}

1 Sinner B, Graf BM. Ketamine. Handb Exp Pharmacol 2008: 31333.

2 Geisslinger G, Hering W, Thomann P, Knoll R, Kamp HD, Brune K. Pharmacokinetics and pharmacodynamics of ketamine enantiomers in surgical patients using a stereoselective analytical method. $\mathrm{Br} \mathrm{J}$ Anaesth 1993; 70: 666-71.

3 Björkman S, Redke F. Clearance of fentanyl, alfentanil, methohexitone, thiopentone and ketamine in relation to estimated hepatic blood flow in several animal species: application to prediction of clearance in man. J Pharm Pharmacol 2000; 52: 1065-74.

4 Restrepo JG, Garcia-Martin E, Martinez C, Agúndez JA. Polymorphic drug metabolism in anaesthesia. Curr Drug Metab 2009; 10: 23646.

5 Capponi L, Schmitz A, Thormann W, Theurillat R, Mevissen M. Invitro evaluation of differences in phase 1 metabolism of ketamine and other analgesics among humans, horses, and dogs. Am J Vet Res 2009; 70: 777-86.

6 Lodge D, Anis NA, Burton NR. Effects of optical isomers of ketamine on excitation of cat and rat spinal neurones by amino acids and acetylcholine. Neurosci Lett 1982; 29: 281-6.

7 Chizh BA. Low dose ketamine: a therapeutic and research tool to explore $N$-methyl-D-aspartate (NMDA) receptor-mediated plasticity in pain pathways. J Psychopharmacol 2007; 21: 259-71.

8 Stahl SM. Mechanism of action of ketamine. CNS Spectrums 2013; 18: $171-4$.

9 Craven R. Ketamine. Anaesthesia 2007; 62 Suppl 1: 48-53.

10 Brown DJ, Brugger H, Boyd J, Paal P. Accidental hypothermia. N Engl J Meg 2012; 367: 1930-8.

11 Olaussen A, Williams B. Intraosseous access in the prehospital 
setting: Literature review. Prehosp Disaster Med 2012; 27: 468-72.

12 Helm M, Hossfeld B, Schlechtriemen T, Braun J, Lampl L, Bernhard M. Use of intraosseous infusion in the German air rescue service: Nationwide analysis in the time period 2005 to 2009. Anaesthesist 2011; 60: 1119-25.

13 Green SM, Roback MG, Kennedy RM, Krauss B. Clinical practice guideline for emergency department ketamine dissociative sedation: 2011 update. Ann Emerg Med 2011; 57: 449-61.

14 Heidari SM, Saghaei M, Hashemi SJ, Parvazinia P. Effect of oral ketamine on the postoperative pain and analgesic requirement following orthopedic surgery. Acta Anaesthesiol Taiwan 2006; 44: 211-5.

15 Fanta S, Kinnunen M, Backman JT, Kalso E. Population pharmacokinetics of S-ketamine and norketamine in healthy volunteers after intravenous and oral dosing. Eur J Clin Pharmacol 2015; 71: 441-7.

16 Huge V, Lauchart M, Magerl W, Schelling G, Beyer A, Thieme D, et al. Effects of lowdose intranasal (S)-ketamine in patients with neuropathic pain. Eur J Pain 2010; 14: 387-94.

17 Green SM, Hummel CB, Wittlake WA, Rothrock SG, Hopkins GA, Garrett W. What is the optimal dose of intramuscular ketamine for pediatric sedation? Acad Emerg Med 1999; 6: 21-6.

18 Sekerci C, Donmez A, Ates Y, Okten F. Oral ketamine premedication in children (placebo controlled double-blind study). Eur J Anaesthesiol 1996; 13: 606-11.

19 Weber F, Wulf H, Gruber M, Biallas R. S-ketamine and s-norketamine plasma concentrations after nasal and iv administration in anesthetized children. Paediatr Anaesth 2004; 14: 983-8.

20 Reid C, Hatton R, Middleton P. Case report: Prehospital use of intranasal ketamine for paediatric burn injury. Emerg Med J 2011; 28: 328-9.

21 Song JW, Shim JK, Song Y, Yang SY, Park SJ, Kwak YL. Effect of ketamine as an adjunct to intravenous atientcontrolled analgesia, in patients at high risk of postoperative nausea and vomiting undergoing lumbar spinal surgery. Br J Anaesth 2013; 111: 630-5.

22 Kye YC, Rhee JE, Kim K, Kim T, Jo YH, Jeong JH, et al. Clinical effects of adjunctive atropine during ketamine sedation in pediatric emergency patients. Am J Emerg Med 2012; 30: 1981-5.

23 Mellon RD, Simone AF, Rappaport BA. Use of anesthetic agents in neonates and young children. Anesth Analg 2007; 104: 509-20.

24 Gutierrez S, Carnes A, Finucane B, Musci G, Oelsner W, Hicks L, et al. Is age-dependent, ketamine-induced apoptosis in the rat somatosensory cortex influenced by temperature? Neuroscience 2010; 168: 253-62.

25 Turner CP, Gutierrez S, Liu C, Miller L, Chou J, Finucane B, et al. Strategies to defeat ketamine-induced neonatal brain injury. Neuroscience 2012; 210: 384-92.

26 Flick RP, Katusic SK, Colligan RC, Wilder RT, Voigt RG, Olson MD, et al. Cognitive and behavioral outcomes after early exposure to anesthesia and surgery. Pediatrics 2011; 128: e1053-61.

27 Chu PS, Ma WK, Wong SC, Chu RW, Cheng $\mathrm{CH}$, Wong S, et al. The destruction of the lower urinary tract by ketamine abuse: a new syndrome? BJU Int 2008; 102: 1616-22.

28 Nomiya A, Nishimatsu H, Homma Y. Interstitial cystitis symptoms associated with ketamine abuse: The first Japanese case. Int J Urol 2011; 18: 735.

29 Poon TL, Wong KF, Chan MY, Fung KW, Chu SK, Man CW, et al. Upper gastrointestinal problems in inhalational ketamine abusers. J Dig Dis 2010; 11: 106-10.

30 Melendez E, Bachur R. Serious adverse events during procedural sedation with ketamine. Pediatr Emerg Care 2009; 25: 325-8.

31 Hudetz JA, Patterson KM, Iqbal Z, Gandhi SD, Byrne AJ, Hudetz
AG, et al. Ketamine attenuates delirium after cardiac surgery with cardiopulmonary bypass. J Cardiothorac Vasc Anesth 2009; 23: 651-7.

32 Laulin JP, Maurette P, Corcuff JB, Rivat C, Chauvin M, Simonnet G. The role of ketamine in preventing fentanyl-induced hyperalgesia and subsequent acute morphine tolerance. Anesth Analg 2002; 94: 1263-9.

33 Gharaei B, Jafari A, Aghamohammadi H, Kamranmanesh M, Poorzamani M, Elyassi $\mathrm{H}$, et al. Opioid-sparing effect of preemptive bolus low-dose ketamine for moderate sedation in opioid abusers undergoing extracorporeal shock wave lithotripsy: a randomized clinical trial. Anesth Analg 2013; 116: 75-80.

34 Niesters M, Khalili-Mahani N, Martini C, Aarts L, van Gerven J, van Buchem MA, et al. Effect of subanesthetic ketamine on intrinsic functional brain connectivity: a placebo-controlled functionalmagnetic resonance imaging study in healthy male volunteers. Anesthesiology 2012; 117: 868-77.

35 Safavi M, Honarmand A, Nematollahy Z. Pre-incisional analgesia with intravenous or subcutaneous infiltration of ketamine reduces postoperative pain in patients after open cholecystectomy: A randomized, doubleblind, placebo-controlled study. Pain Med 2011; 12: 1418-26.

36 Loftus RW, Yeager MP, Clark JA, Brown JR, Abdu WA, Sengupta $\mathrm{DK}$, et al. Intraoperative ketamine reduces perioperative opiate consumption in opiate-dependent patients with chronic back pain undergoing back surgery. Anesthesiology 2010; 113: 639-46.

37 Riham Hasanein, Wael El-Sayed, Nashwa Nabil, Ghada Elsayed. The effect of combined remifentanil and low dose ketamine infusion in patients undergoing laparoscopic gastric bypass. Egypt J Anaesthesiol 2011; 27: 255-60.

38 Feltracco P, Barbieri S, Rizzi S, Ori C, Groppa F, De Rosa G, et al. Perioperative analgesic efficacy and plasma concentrations of $S(+)$ ketamine in continuous epidural infusion during thoracic surgery. Anesth Analg 2013; 116: 1371-5.

39 Nitta R, Goyagi T, Nishikawa T. Combination of oral clonidine and intravenous low-dose ketamine reduces the consumption of postoperative patient-controlled analgesia morphine after spine surgery. Acta Anaesthesiol Taiwan 2013; 51: 14-7.

40 Atashkhoyi S, Negargar S, Hatami-Marandi P. Effects of the addition of low-dose ketamine to propofol-fentanyl anaesthesia during diagnostic gynaecological laparoscopy. Eur J Obstet Gynecol Reprod Biol 2013; 170: 247-50.

41 Bauchat JR, Higgins N, Wojciechowski KG, McCarthy RJ, Toledo P, Wong CA. Lowdose ketamine with multimodal ostcesarean delivery analgesia: A randomized controlled trial. Int J Obstet Anesth 2011; 20: 3-9.

42 Suppa E, Valente A, Catarci S, Zanfini BA, Draisci G. A study of low-dose S-ketamine infusion as "preventive" pain treatment for cesarean section with spinal anesthesia: benefits and side effects. Minerva Anestesiol 2012; 78: 774-81.

43 Leal PC, Sakata RK, Salomão R, Sadatsune EJ, Issy AM. Assessment of the effect of ketamine in combination with remifentanil on postoperative pain. Braz J Anesthesiol 2013; 63: 178-82.

44 Bilgen S, Köner O, Türe H, Menda F, Fiçicioğlu C, Aykaç B. Effect of three different doses of ketamine prior to general anaesthesia on postoperative pain following Caesarean delivery: A prospective randomized study. Minerva Anestesiol 2012; 78: 442-9.

45 Sahin L, Sahin M, Aktas O, Kilic E, Mandollu E. Comparison of propofol/ketamine versus propofol/alfentanil for dilatation and curettage. Clin Exp Obstet Gynecol 2012; 39: 72-5.

46 Morris C, Perris A, Klein J, Mahoney P. Anaesthesia in haemo- 
dynamically compromised emergency patients: Does ketamine represent the best choice of induction agent? Anaesthesia 2009; 64: 532-9.

47 Braun P, Wenzel V, Paal P. Anesthesia in prehospital emergencies and in the emergency department. Curr Opin Anaesthesiol 2010; 23: $500-6$.

48 Hudetz JA, Pagel PS. Neuroprotection by ketamine: a review of the experimental \& clinical evidence. J Cardiothorac Vasc Anesth 2010; 24: 131-42.

49 Sehdev RS, Symmons DA, Kindl K. Ketamine for rapid sequence induction in patients with head injury in the emergency department. Emerg Med Australas 2006; 18: 37-44.

50 McGuinness SK, Wasiak J, Cleland H, Symons J, Hogan L, Hucker T, et al. A systematic review of ketamine as an analgesic agent in adult burn injuries. Pain Med 2011; 12: 1551-8.

51 Jennings PA, Cameron P, Bernard S, Walker T, Jolley D, Fitzgerald $\mathrm{M}$, et al. Morphine and ketamine is superior to morphine alone for out-ofhospital trauma analgesia: A randomized controlled trial. Ann Emerg Med 2012; 59: 497-503.

52 Bredmose PP, Lockey DJ, Grier G, Watts B, Davies G. Pre-hospital use of ketamine for analgesia and procedural sedation. Emerg Med J 2009; 26: 62-4.

53 Green SM, Andolfatto G, Krauss B. Ketofol for procedural sedation? Pro and con. Ann Emerg Med 2011; 57: 444-8.

54 Scheier E, Gadot C, Leiba R, Shavit I. Sedation with the combination of ketamine and propofol in a pediatric ED: a retrospective case series analysis. Am J Emerg Med 2015; 33: 815-7.

55 Miner JR, Gray RO, Bahr J, Patel R, McGill JW. Randomized clinical trial of propofol versus ketamine for procedural sedation in the emergency department. Acad Emerg Med 2010; 17: 604-11.

56 Prossliner $\mathrm{H}$, Braun P, Paal P. Anaesthesia in medical emergencies. Trends Anaesth Crit Care 2012; 2: 109-14.

57 Cevik E, Bilgic S, Kilic E, Cinar O, Hasman H, Acar AY, et al. Comparison of ketamine-low-dose midozolam with midazolam-fentanyl for orthopedic emergencies: a double-blind randomized trial. Am J Emerg Med 2013; 31: 108-13.

58 Ahern TL, Herring AA, Stone MB, Frazee BW. Effective analgesia with low-dose ketamine and reduced dose hydromorphone in ED patients with severe pain. American Journal of Emergency Medicine 2013; 31: 847-51.

59 Ahern TL, Herring AA, Anderson ES, Madia VA, Fahimi J, Frazee BW. The first 500: initial experience with widespread use of low-dose ketamine for acute pain management in the ED. Am J Emerg Med 2015; 33: 197-201.

60 Ahern TL, Herring AA, Miller S, Frazee BW. Low-dose ketamine infusion for emergency department patients with severe pain. Pain Med 2015; 16: 1402-9.

61 Motov S, Rockoff B, Cohen V, Pushkar I, Likourezos A, McKay C, et al. Intravenous subdissociative-dose ketamine versus morphine for analgesia in the emergency department: a randomized controlled trial. Ann Emerg Med 2015; 66: 222-9.e1.

62 Andolfatto G, Willman E, Joo D, Miller P, Wong WB, Koehn M, et al. Intranasal ketamine for analgesia in the emergency department: a prospective observational series. Acad Emerg Med 2013; 20: 10504.

63 Yeaman F, Oakley E, Meek R, Graudins A. Sub-dissociative dose intranasal ketamine for limb injury pain in children in the emergency department: A pilot study. Emerg Med Australas 2013; 25: 161-7.

64 Olaussen A, Williams B. Intraosseous access in the prehospital setting: literature review. Prehosp Disaster Med 2012; 27: 468-72.

65 Schnabel A, Poepping DM, Kranke P, Zahn PK, Pogatzki-Zahn EM.
Efficacy and adverse effects of ketamine as an additive for paediatric caudal anaesthesia: a quantitative systematic review of randomized controlled trials. Br J Anaesth 2011; 107: 601-11.

66 Dahmani S, Michelet D, Abback PS, Wood C, Brasher C, Nivoche $\mathrm{Y}$, et al. Ketamine for perioperative pain management in children: A metaanalysis of published studies. Paediatr Anaesth 2011; 21: 636-52.

67 Elshammaa N, Chidambaran V, Housny W, Thomas J, Zhang X, Michael R. Ketamine as an adjunct to fentanyl improves postoperative analgesia and hastens discharge in children following tonsillectomy - a prospective, doubleblinded, randomized study. Paediatr Anaesth 2011; 21: 1009-14.

68 Kim KS, Kwak HJ, Min SK, Lee SY, Kim KM, Kim JY. The effect of ketamine on tracheal intubating conditions without neuromuscular blockade during sevoflurane induction in children. J Anesth 2011; 25: 195-9.

69 Jha AK, Bhardwaj N, Yaddanapudi S, Sharma RK, Mahajan JK. A randomized study of surgical site infiltration with bupivacaine or ketamine for pain relief in children following cleft palate repair. Pediatr Anesth 2013; 23: 401-6.

70 Javid MJ, Hajijafari M, Hajipour A, Makarem J, Khazaeipour Z. Evaluation of low dose ketamine in post tonsillectomy pain relief: a randomized trial comparing intravenous and subcutaneous ketamine in pediatrics. Anesth Pain Med 2012; 2: 85-9.

71 Tekelioglu UY, Apuhan T, Akkaya A, Demirhan A, Yildiz I, Simsek T, et al. Comparison of topical tramadol and ketamine in pain treatment after tonsillectomy. Pediatr Anesth 2013; 23: 496-501.

72 Ugur KS, Karabayirli S, Demircioğlu Ri, Ark N, Kurtaran H, Muslu $\mathrm{B}$, et al. The comparison of preincisional peritonsillar infiltration of ketamine and tramadol for postoperative pain relief on children following adenotonsillectomy. Int J Pediatr Otorhinolaryngol 2013; 77: 1825-9.

73 Nielsen BN, Friis SM, Rømsing J, Schmiegelow K, Anderson BJ, Ferreirós $\mathrm{N}$, et al. Intranasal sufentanil/ketamine analgesia in children. Pediatr Anesth 2014; 24: 170-80.

74 Norambuena C, Yañez J, Flores V, Puentes P, Carrasco P, Villena R. Oral ketamine and midazolam for pediatric burn patients: A prospective, randomized, double-blind study. J Pediatr Surg 2013; 48: 629-34.

75 Pestieau SR, Finkel JC, Junqueira MM, Cheng Y, Lovejoy JF, Wang J, et al. Prolonged perioperative infusion of low-dose ketamine does not alter opioid use after pediatric scoliosis surgery. Pediatr Anesth 2014; 24: 582-90.

76 Visser E, Schug SA. The role of ketamine in pain management. Biomed Pharmacother 2006; 60: 341-8.

77 Bredlau AL, Thakur R, Korones DN, Dworkin RH. Ketamine for pain in adults and children with cancer: A systematic review and synthesis of the literature. Pain Med 2013; 14: 1505-17.

78 Marchetti F, Coutaux A, Bellanger A, Magneux C, Bourgeois P, Mion G. Efficacy and safety of oral ketamine for the relief of intractable chronic pain: A retrospective 5-year study of 51 patients. Eur J Pain 2014; 19: 984-93.

79 Barreveld AM, Correll DJ, Liu X, Max B, McGowan JA, Shovel L, et al. Ketamine decreases postoperative pain scores in patients taking opioids for chronic pain: results of a prospective, fandomized, doubleblind study. Pain Med 2013; 14: 925-34.

80 Amr YM. Multi-day Low dose ketamine infusion as a djuvant to oral gabapentin in spinal cord injury related chronic pain: a prospective, randomized, double blind trial. Pain Physician 2010; 13: 245-9.

81 Hardy J, Quinn S, Fazekas B, Plummer J, Eckermann S, Agar M, et al. Randomized, double-blind, placebo-controlled study to assess the 
efficacy and toxicity of subcutaneous ketamine in the management of cancer pain. J Clin Oncol 2012; 30: 3611-7.

82 Tena B, Gomar C, Rios J. Perioperative epidural or intravenous ketamine does not improve the effectiveness of thoracic epidural analgesia for acute and chronic pain after thoracotomy. Clin J Pain 2014; 30: 490-500.

83 Schug SA, Goddard C. Recent advances in the pharmacological management of acute and chronic pain. Ann Palliat Med 2014; 3: 263-75.

84 Reardon S. Rave drug tested against depression: Companies and clinicians turn to ketamine to treat mental-health disorder as pipeline of new drugs dries up. Nature 2015; 517: 130-1.

85 Salvadore G, Singh JB. Ketamine as a fast acting antidepressant: current knowledge and open questions. CNS Neurosci Ther 2013; 19: 428-36.

86 Nugent AC, Diazgranados N, Carlson PJ, Ibrahim L, Luckenbaugh DA, Brutsche N, et al. Neural correlates of rapid antidepressant response to ketamine in bipolar disorder. Bipolar Disord 2014; 16: 119-28.

87 Lee EE, Della Selva MP, Liu A, Himelhoch S. Ketamine as a novel treatment formajor depressive disorder and bipolar depression: a systematic review and quantitative meta-analysis. Gen Hosp Psychiatry 2015; 37: 178-84.

88 Ibrahim L, Diazgranados N, Franco-Chaves J, Brutsche N, Henter ID, Kronstein $\mathrm{P}$, et al. Course of improvement in depressive symptoms to a single intravenous infusion of ketamine vs add-on riluzole: results from a 4-week, double-blind, placebo controlled study. Neuropsychopharmacology 2012; 37: 1526-33.

89 Mathew SJ, Murrough JW, aan het Rot M, Collins KA, Reich DL, Charney DS. Riluzole for relapse prevention following intravenous ketamine in treatment-resistant depression: a pilot randomized, placebo-controlled continuation trial. Int J Neuropsychopharmacol 2010; 13: 71-82.

90 Reinstatler L, Youssef NA. Ketamine as a Potential treatment for suicidal ideation: a systematic review of the literature. Drugs $R D$ 2015; 15: 37-43.

91 Murrough JW, losifescu DV, Chang LC, Al Jurdi RK, Green CE, Perez AM, et al. Antidepressant efficacy of ketamine in treatment-resistant major depression: a two-site, randomized, parallel-arm, midazolamcontrolled clinical trial. Am J Psychiatry 2013; 170: 1134-42.
$\mathrm{M}$, et al. Rapid and longer-term antidepressant effects of repeated ketamine infusions in treatment-resistant major depression. Biol Psychiatry 2013; 74: 250-6.

93 Price RB and Mathew SJ. Does ketamine have anti-suicidal properties? Current status and future directions. CNS Drugs 2015; 29: 181-8.

94 Price RB, losifescu DV, Murrough JW, Chang LC, Al Jurdi RK, Iqbal SZ, et al. Effects of ketamine on explicit and implicit suicidal cognition: a randomized controlled trial in treatment-resistant depression. Depress Anxiety 2014; 31: 335-43.

95 Iglewicz A, Morrison K, Nelesen RA, Zhan T, Iglewicz B, Fairman N, et al. Ketamine for the treatment of depression in patients receiving hospice care: a retrospective medical record review of thirty-one cases. Psychosomatics 2014; 56: 329-37.

96 De Kock M, Loix S, Lavand'homme P. Ketamine and peripheral inflammation. CNS Neurosci Ther 2013; 19: 403-10.

97 Dhote F, Carpentier P, Barbier L, Peinnequin A, Baille V, Pernot F, et al. Combinations of ketamine and atropine are neuroprotective and reduce neuroinflammation after toxic status epilepticus in mice. Toxicol Appl Pharmacol 2012; 259: 195-209.

98 Dale O, Somogyi AA, Li Y, Sullivan T, Shavit Y. Does intraoperative ketamine attenuate inflammatory reactivity following surgery? A systematic review and meta-analysis. Anesth Analg 2012; 115: 934-43.

99 Gao M, Qian Y, Ji L, Feng G, Sun J. Effect of N-methyl-D-aspartate receptor antagonist on $\mathrm{T}$ helper cell differentiation induced by phorbol-myristate-acetate and ionomycine. Cytokines 2011; 56: 458-65.

100 Gao M, Sun J, Jin W, Qian Y. Morphine, but not ketamine, decreases the ratio of Th1/Th2 in CD4-positive cells through T-bet and GATA3. Inflammation 2012; 35: 1069-77.

101 Remerand F, Le Tendre Ch, Baud A, Couvret C, Pourrat X, Favard L, et al. The early and delayed analgesic effects of ketamine after total hip arthroplasty: a prospective, randomized, controlled, double-blind study. Anesth Analg 2009; 109: 1963-7.

102 Welters ID, Feurer MK, Preiss V, Müller M, Scholz S, Kwapisz M, et al. Continuous S-(+)-ketamine administration during elective coronary artery bypass graft surgery attenuates pro-inflammatory cytokine response during and after cardiopulmonary bypass. Br J Anaesth 2011; 106: 172-9. 